\title{
Influence of low- and high-elevation plant genomes on the regulation of autumn cold acclimation in Abies sachalinensis
}

\author{
Wataru Ishizuka ${ }^{1 *}$, Kiyomi Ono², Toshihiko Hara² and Susumu Goto ${ }^{3}$ \\ ${ }^{1}$ Forestry Research Institute, Hokkaido Research Organization, Bibai, Japan, ${ }^{2}$ Institute of Low Temperature Science, \\ Hokkaido University, Sapporo, Japan, ${ }^{3}$ Graduate School of Agricultural and Life Sciences, The University of Tokyo, Tokyo, \\ Japan
}

Boreal coniferous species with wide geographic distributions show substantial variation in autumn cold acclimation among populations. To determine how this variation is inherited across generations, we conducted a progeny test and examined the development of cold hardening in open-pollinated second-generation $\left(F_{2}\right)$ progeny of Abies sachalinensis. The $F_{1}$ parents had different genetic backgrounds resulting from reciprocal interpopulational crosses between low-elevation $(L)$ and high-elevation $(H)$

OPEN ACCESS

Edited by:

Glenn Thomas Howe,

Oregon State University, USA

Reviewed by:

Jason Holliday,

Virginia Polytechnic Institute and State

University, USA

Anne Y. Fennell,

South Dakota State University, USA

*Correspondence:

Wataru Ishizuka

wataru.ishi@gmail.com

Specialty section:

This article was submitted to

Functional Plant Ecology,

a section of the journal

Frontiers in Plant Science

Received: 31 August 2014

Accepted: 07 October 2015

Published: 21 October 2015

Citation:

Ishizuka W, Ono K, Hara T and Goto S (2015) Influence of lowand high-elevation plant genomes on

the regulation of autumn cold acclimation in Abies sachalinensis.

Front. Plant Sci. 6:890.

doi: 10.3389/fpls.2015.00890 populations: $\mathrm{L} \times \mathrm{L}, \mathrm{L} \times \mathrm{H}, \mathrm{H} \times \mathrm{L}$, and $\mathrm{H} \times \mathrm{H}$. Paternity analysis of the $\mathrm{F}_{2}$ progeny using molecular genetic markers showed that $91.3 \%$ of the fathers were located in surrounding stands of the $F_{1}$ planting site (i.e., not in the $F_{1}$ test population). The remaining fathers were assigned to $F_{1}$ parents of the $L \times L$ cross-type. This indicates that the high-elevation genome in the $F_{1}$ parents was not inherited by the $F_{2}$ population via pollen flow. The timing of autumn cold acclimation in the $F_{2}$ progeny depended on the cross-type of the $\mathrm{F}_{1}$ mother. The progeny of $\mathrm{H} \times \mathrm{H}$ mothers showed less damage in freezing tests than the progeny of other cross-types. Statistical modeling supported a linear effect of genome origin. In the best model, variation in freezing damage was explained by the proportion of maternally inherited high-elevation genome. These results suggest that autumn cold acclimation was partly explained by the additive effect of the responsible maternal genome. Thus, the offspring that inherited a greater proportion of the high-elevation genome developed cold hardiness earlier. Genome-based variation in the regulation of autumn cold acclimation matched the local climatic conditions, which may be a key factor in elevation-dependent adaptation.

Keywords: cold acclimation, interpopulation variation, elavational cline, phenology, Abies sachalinensis, modeling, paternity analysis

\section{INTRODUCTION}

Seasonal growth cycles are well described for plant taxa distributed in boreal, sub-boreal, and temperate climates. In particular, for evergreen coniferous species, cold acclimation often occurs before temperatures drop below freezing (Aitken and Hannerz, 2001; Chuine, 2010). During this acclimation, evergreen plants shift their physiological condition from an active growth phase to a hardening phase that involves some degree of freezing tolerance. This physiological shift is 
responsible for a series of mechanical and biochemical changes in the cell: for example, intracellular accumulation of compatible osmolytes such as soluble sugars, accumulation of polypeptides and/or proteins, and the vesiculation of vacuoles (Fujikawa et al., 2006). The timing of cold acclimation affects fitness. A long duration of the hardy phase may help plants avoid autumn and spring freezing damage. However, it can also limit annual photosynthetic activity and growth. Therefore, because of a trade-off between growth and risk of freezing damage, the timing of phenological events can be a key driver for adaptation to cold climates. During their long evolutionary histories, conifers have acquired an adaptive schedule of cold acclimation to survive under their local environmental conditions, using changes in daylength and/or temperature as regulatory signals (Kozlowski and Pallardy, 2002). Population differences in the acclimation schedule can be observed within species that inhabit wide geographic distributions spanning diverse climatic regions. Interpopulational genetic variation in phenological traits is associated with climatic differences (Rehfeldt, 1989; Oleksyn et al., 1998). Furthermore, interpopulational genetic variation for many boreal conifers is greater during autumn cold acclimation than during spring dehardening (Aitken and Hannerz, 2001; Howe et al., 2003). It is a consistent trend that populations from high latitudes and elevations exhibit earlier development of cold hardening than those from low latitudes or elevations (Rehfeldt, 1989; Skrøppa and Magnussen, 1993; Oleksyn et al., 1998; Savolainen et al., 2004; Notivol et al., 2007; Mimura and Aitken, 2010).

Common garden trials and reciprocal transplantation experiments are powerful tools for detecting adaptive variation in plants and the drivers of natural selection. A previous study using transplanted materials of the sub-boreal conifer Abies sachalinensis Mast. (Sakhalin fir) has revealed an adaptive cline in the timing of autumn cold acclimation along an elevational gradient (Ishizuka et al., 2015). In that study, earlier development of autumn cold acclimation in trees derived from high-elevation populations than in those from low-elevation populations was detected at all transplantation sites. Modeling analysis was then conducted to examine the environmental conditions responsible for the detected physiological variation. The results have shown that the genetic variation in response to the temperature change might be an important driver of elevation-dependent adaptation (Ishizuka et al., 2015). However, the mechanisms by which the genome generates quantitative adaptive differences are not clearly understood. Quantitative traits resulting as a consequence of genome inheritance and genome effects are complex (Sykes et al., 2006; Cané-Retamales et al., 2011). Furthermore, some studies have reported epigenetic phenomena which have regulated phenological traits (Johnsen et al., 2005; Kvaalen and Johnsen, 2008). Perennial plants have a "memory" of the climate they experienced during embryogenesis. These epigenetic signals may be transmitted through several mechanisms, including cytosine methylation and histone modification, and may enhance adaptation at a population level (Johnsen et al., 2005; Kvaalen and Johnsen, 2008). Controlled crosses using mother plants that have been exposed to the same environmental conditions can be used to test the effects of genome inheritance on the regulation of the autumn cold acclimation. However, previous ecological studies have not extensively evaluated the complex effects of genome inheritance on the development of cold acclimation in trees.

We investigated the genetic basis of variation in the regulation of autumn cold acclimation using Sakhalin fir. This conifer plays an important role in the timber production in northern Japan. It is a dominant climax species in natural sub-boreal forests of the Far East, thus forming an important component of forest ecosystems (Kato, 1952). The geographic range of this species extends from eastern Siberia to Hokkaido, the northernmost island of the Japanese archipelago (Figure 1A). The elevational distribution extends from 100 to $1600 \mathrm{~m}$ a.s.l. This species survived in a glacial refugium in Hokkaido, and had become a dominant species by the time of the last glacial maximum, 20000 years ago (Igarashi, 1996; Tsumura and Suyama, 1998). Interpopulational variation in several traits has been observed within this elevational range, including variation in growth and survival (Goto et al., 2011; Ishizuka and Goto, 2012), resistance to biological stresses such as disease or rats (Kurahashi and Hamaya, 1981; Saho et al., 1994), and cold hardiness (Eiga and Sakai, 1984). In our recent study, we reported that clinal variation in the timing of cold acclimation appears to result from adaptation to the local climate at elevations ranging from 230 to 1200 m (Ishizuka et al., 2015).

In the present study, we used open pollination to obtain second-generation $\left(\mathrm{F}_{2}\right)$ progeny for testing the genetic basis of variation in phenological traits. The maternal population $\left(\mathrm{F}_{1}\right)$ was produced by reciprocal crosses between two distinct ecotypes: a population inhabiting low elevations and a population inhabiting high elevations. The genetic background of the maternal $F_{1}$ trees varied among cross-types (low $\times$ low, hybrids between elevations, high $\times$ high), and the trees were planted at a single site in order to ensure their exposure to the same environment. Thus, we could evaluate the effects of genome inheritance by examining the traits of the $F_{2}$ population. Using the $F_{2}$ progeny, we conducted (1) paternity analysis based on microsatellite markers and (2) statistical modeling of freezing damage. Our objectives were to (1) measure variation in the timing of autumn cold acclimation of the $F_{2}$ progeny and (2) establish whether this variation could be explained by the genomic background inherited from the low-elevation or high-elevation populations.

\section{MATERIALS AND METHODS}

\section{$F_{1}$ Planting Site}

We conducted this study in the University of Tokyo Hokkaido Forest (UTHF), located in central Hokkaido, northern Japan $\left(43^{\circ} 20^{\prime} \mathrm{N}, 142^{\circ} 30^{\prime} \mathrm{E}\right.$; Figure 1A). In the UTHF, natural subboreal forests cover about $150 \mathrm{~km}^{2}$ of the south-western slope of Mt. Dairoku (1459 m a.s.l.), with an elevational gradient of more than $1200 \mathrm{~m}$. With increasing elevation, dramatic changes occur in soil type, snow depth, and forest vegetation, including changes in the prevalence of the bamboo species, Sasa senanensis and Stigmella kurilensis (Kato, 1952; Toyooka et al., 1983; Nakata et al., 1994). However, the primary factor changing 

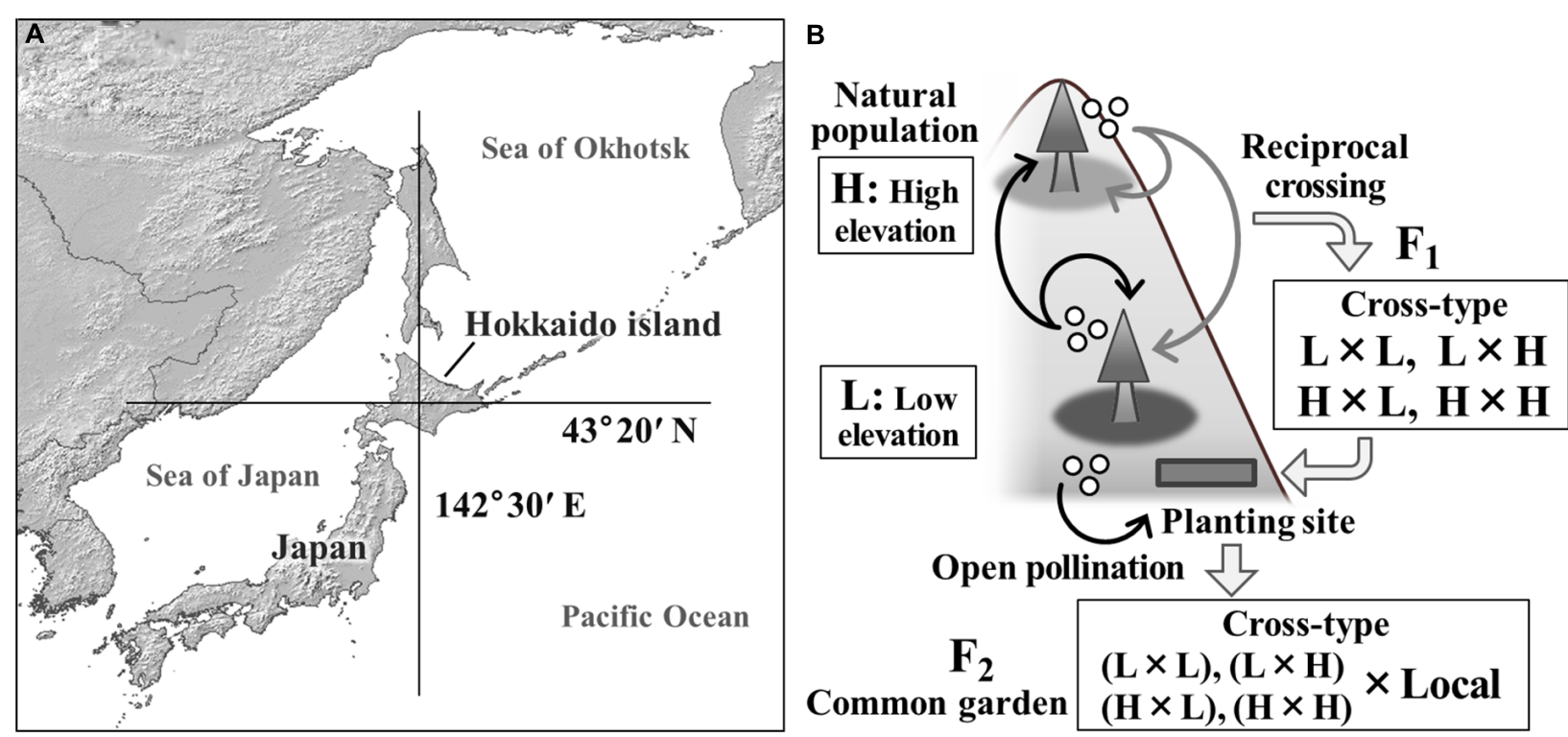

FIGURE 1 | A map of the study site (A) and the experimental design using $\mathrm{F}_{\mathbf{2}}$ progeny of interpopulational crosses of $A$ bies sachalinensis (B). Two natural populations used for crossing were located where the latitudinal and longitudinal lines cross in panel (A). A planting site of the $F_{1}$ population and a common garden trial for the $F_{2}$ progeny were established in the same area. The $F_{1}$ population was produced using reciprocal crossing between low-elevation ( $L$ ) and high-elevation $(H)$ populations in 1979. Open-pollinated seeds were collected from the $F_{1}$ mother trees in 2009 . The resulting $F_{2}$ progeny had various genetic backgrounds resulting from the maternal cross-type.

with elevation is air temperature. Based on monitoring data recorded hourly from 2009 to 2010 at $230 \mathrm{~m}$, the annual and winter (October-March) mean temperatures were $6.53^{\circ} \mathrm{C}$ and $-1.78^{\circ} \mathrm{C}$, respectively. Temperatures at $1100 \mathrm{~m}$ were $1.75^{\circ} \mathrm{C}$ and $-6.43^{\circ} \mathrm{C}$, respectively.

Sakhalin fir, A. sachalinensis, grows from the lowland (200 m) to the high-elevation zone $(1200 \mathrm{~m})$ in this area. In 1979, natural populations at $400-530 \mathrm{~m}$ and $1100-1200 \mathrm{~m}$ were selected as lowelevation (L) and high-elevation $(\mathrm{H})$ populations, respectively, and artificial reciprocal crossing was performed by Kurahashi (Kurahashi, 1995; Goto et al., 2011). Within each population, five and three adult trees were selected as mother (seed parents) and father trees (pollen donors), respectively (Kurahashi and Hamaya, 1981). Pollen from the three father trees in each population was pooled and used for the crosses. The generated progeny were categorized into four cross-types (female $\times$ male): $\mathrm{L} \times \mathrm{L}, \mathrm{L} \times \mathrm{H}, \mathrm{H} \times \mathrm{L}$, and $\mathrm{H} \times \mathrm{H}$ (Figure 1B). We refer to these progeny as the $F_{1}$ population. Seedlings of the $F_{1}$ population were grown in an outdoor nursery at a lowland site of the UTHF. In 1986, the $F_{1}$ individuals were transplanted to the lowland planting site (220 m; Figure 1B). At the planting site, the progeny were arrayed in grids at a spacing of $1.2 \mathrm{~m}$, assigning one block ( 2 columns $\times 10$ rows) to each cross-treatment. Unreplicated blocks were used to avoid contamination among treatments (Kurahashi, 1995). In total, $440 \mathrm{~F}_{1}$ seedlings were transplanted. Thus, the $F_{1}$ populations had varying genetic backgrounds but were exposed to the same environmental conditions. Further information about the traits measured on the $\mathrm{F}_{1}$ trees (survival, height, diameter at breast height, leaf nitrogen content, and leaf area per weight) were provided by Goto et al. (2011).

\section{Seed Collection from the $\mathbf{F}_{\mathbf{1}}$ Generation}

In 2009, 23 years after planting, $353 \mathrm{~F}_{1}$ trees were alive and some of them were in a reproductive stage. Our field surveys during the flowering and seed-maturing seasons showed that 22 trees flowered that year at the $F_{1}$ planting site (Table 1). We collected open-pollinated seeds from the flowering trees on September 6th and 9th, 2009. We selected $13 \mathrm{~F}_{1}$ mother trees that produced a sufficient number of progeny ( $>20$ cones) to use in this study (Table 1; see the Supplemental Table for ID-information of the mother trees). The progeny ( $F_{2}$ population) were grouped into four types according to the maternal cross category: $\mathrm{L} \times \mathrm{L}, \mathrm{L} \times \mathrm{H}$, $\mathrm{H} \times \mathrm{L}$, and $\mathrm{H} \times \mathrm{H}$ (Figure 1B). Collected seeds were stored at $-3^{\circ} \mathrm{C}$ until use.

\section{$F_{2}$ Common Garden Trial}

We conducted a common garden trial of the $\mathrm{F}_{2}$ progeny. Before the trial, viable seeds were selected from all collected seeds using soft X-ray photography (Softex, Kanagawa, Japan). In the spring of 2010, the viable seeds were subjected to a seed stratification treatment and were sown into the UTHF nursery (230 $\mathrm{m}$ a.s.l.; Figure 1A). One seed was placed in each $4-\mathrm{cm}$ grid of a $1.0 \mathrm{~m} \times 1.2 \mathrm{~m}$ block to maintain the identity of all germinated seedlings. The four blocks were separated by buffer spaces. To avoid edge effects for the $\mathrm{F}_{2}$ progeny, control seeds were also sown at the edge of the rows and columns. In total, 2112 seeds were sown in this trial (four blocks $\times 22$ rows $\times 24$ columns). The seedlings were raised until the end of the second growing season. As shown in Table 2, the cross-type differences of the mother of the $\mathrm{F}_{2}$ progeny were reflected in some functional traits, such as the germination rates and 2-year heights. 
TABLE 1 | Number of $F_{1}$ trees of Abies sachalinensis that were living, flowering, or used to collect open-pollinated seeds in 2009.

\begin{tabular}{lccc}
\hline Cross-type & Living & Flowering & Seed collection \\
\hline $\mathrm{L} \times \mathrm{L}$ & 144 & 7 & 3 \\
$\mathrm{~L} \times \mathrm{H}$ & 62 & 4 & 3 \\
$\mathrm{H} \times \mathrm{L}$ & 59 & 4 & 3 \\
$\mathrm{H} \times \mathrm{H}$ & 88 & 7 & 4 \\
Total & 353 & 22 & 13 \\
\hline
\end{tabular}

Four types of $F_{1}$ trees were planted at $220 \mathrm{~m}$ a.s.l. These trees were originated from controlled reciprocal crosses between low-elevation $(L)$ and high-elevation $(H)$ populations.

TABLE 2 | Germination rates and 2-year heights of $F_{2}$ progeny in a common garden trial at $230 \mathrm{~m}$ a.s.l.

\begin{tabular}{lcc}
\hline Cross-type of mother & Germination rate (\%) & 2-year height (mm) \\
\hline $\mathrm{L} \times \mathrm{L}$ & $82.7(16.1)$ & $80.1(21.6)$ \\
$\mathrm{L} \times \mathrm{H}$ & $76.3(12.8)$ & $72.6(20.0)$ \\
$\mathrm{H} \times \mathrm{L}$ & $81.3(13.2)$ & $77.5(17.6)$ \\
$\mathrm{H} \times \mathrm{H}$ & $73.8(7.8)$ & $63.6(18.7)$ \\
Total & $79.3(14.0)$ & $74.7(20.9)$ \\
\hline
\end{tabular}

The $F_{2}$ progeny were categorized into four cross-types, according to the crosstypes of the $F_{1}$ mother trees. Standard deviations are shown in parentheses.

\section{Genotyping using SSR Markers}

To estimate the genome composition of the $F_{2}$ progeny, we performed molecular genetic analysis using nuclear microsatellite (nSSR) and chloroplast microsatellite (cpSSR) markers. In the present study, we used four nSSRs: As08, As16, As32 (Lian et al., 2007), and NFH 15 (Hansen et al., 2005), and three cpSSRs: pt30204, pt71936 (Vendramin et al., 1996), and pt30249 (Liepelt et al., 2001).

Samples selected for SSR genotyping consisted of the 22 flowering $F_{1}$ trees described in Table 1 plus 80 of their $F_{2}$ progeny. These $80 \mathrm{~F}_{2}$ progeny were derived from seeds collected in 2009, and were composed of 16 progeny from each of five $F_{1}$ trees selected across the cross-types (Table 3 ). These seedlings were germinated in an indoor growth chamber.

For the DNA extractions, foliage was collected from the 22 candidate $\mathrm{F}_{1}$ trees and the $80 \mathrm{~F}_{2}$ progeny. DNA was extracted using the DNeasy Plant Mini Kit (Qiagen, Ltd., Crawley, UK), and the PCR reactions were performed using the Multiplex PCR Kit (Qiagen, Ltd., Crawley, UK) following the protocol of Lian et al. (2007). The PCR products were sequenced using an Applied Biosystems 3130xl Genetic Analyzer (Life Technologies, Carlsbad, CA, USA). Genotyping of all samples was performed based on the length of each sequenced fragment using Peak Scanner ver. 1.0 software from Applied Biosystems. Genetic diversity statistics were calculated by GenAlEx ver. 6.5 (Peakall and Smouse, 2012).

\section{Paternity Analysis}

We considered the 22 flowering $F_{1}$ trees as candidate pollen parents of the $F_{2}$ progeny because no other trees were flowering at the $F_{1}$ planting site. However, trees outside of the $F_{1}$ population
TABLE 3 | Genetic diversity statistics of the $F_{1}$ trees that flowered in 2009 and their open-pollinated $F_{2}$ progeny.

\begin{tabular}{|c|c|c|c|c|c|c|}
\hline Population & Mother & $N$ & $A$ & Ho & $H_{\mathrm{E}}$ & $F_{\text {IS }}$ \\
\hline \multicolumn{2}{|c|}{$F_{1}$ (flowered in 2009) } & 22 & 10.3 & 0.864 & 0.838 & -0.033 \\
\hline \multirow[t]{6}{*}{$\mathrm{F}_{2}$} & As- $F_{1}-\mathrm{C} 034$ & 16 & 9.0 & 0.875 & 0.735 & -0.199 \\
\hline & As- $F_{1}-\mathrm{C} 042$ & 16 & 7.5 & 0.906 & 0.750 & -0.216 \\
\hline & As- $F_{1}-C_{148}$ & 16 & 8.8 & 0.906 & 0.757 & -0.198 \\
\hline & As- $F_{1}-C 168$ & 16 & 7.8 & 0.906 & 0.749 & -0.212 \\
\hline & As- $F_{1}-C 061$ & 16 & 8.8 & 0.906 & 0.771 & -0.175 \\
\hline & Total & 80 & 8.4 & 0.900 & 0.752 & -0.200 \\
\hline
\end{tabular}

$N$, number of individuals sampled; $A$, average number of alleles; $H_{O}$, observed heterozygosity; $H_{E}$, expected heterozygosity; $F_{I S}$, fixation index.

may have also served as pollen parents because the $\mathrm{F}_{1}$ planting site was surrounded by mature artificial forests. The origin of these artificial forests was a local lowland forest $(200-300 \mathrm{~m})$ that was different from the forests used to create the $F_{1}$ population.

For paternity analysis, we first inferred paternity of the $\mathrm{F}_{2}$ progeny using four nSSRs. Using CERVUS 3.0 (Kalinowski et al., 2007), we compared the nSSRs genotypes of the $80 \mathrm{~F}_{2}$ progeny to their known seed parents (mothers) and 22 candidate $\mathrm{F}_{1}$ pollen parents (fathers). The most likely father was estimated using maximum-likelihood assignment from the possible allele combinations (genotypes) of the parents. When none of the potential $F_{1}$ donors were assigned as fathers, we considered pollen contamination and genotyping errors as possible causes. Genotyping errors can lead to inflated estimates of outside pollen flow (Slavov et al., 2005). We set the genotyping error to $1 \%$ with an $80 \%$ confidence level for the 10000 cycle-simulations for the paternity assignment.

After assigning fathers using CERVUS, we performed a simple exclusion procedure using three cpSSRs. The $\mathrm{F}_{2}$ progeny and the assumed $\mathrm{F}_{1}$ pollen parents were required to have matching cpSSR haplotypes (Abies cpSSRs are paternally inherited; Vendramin and Ziegenhagen, 1997). We assumed that CERVUS assigned the correct pollen parent when the genotypes of the $\mathrm{F}_{2}$ progeny and assigned pollen parent matched for all three cpSSR markers (considering genotyping errors). When a complete match was not found, we assumed the pollen came from outside of the $F_{1}$ planting site.

Combining the results from CERVUS and the exclusion procedure, we estimated the proportion of selfed seeds, seeds sired by the $F_{1}$ population, and seeds sired by fathers outside the studied $\mathrm{F}_{1}$ population. We also estimated the composition of the $\mathrm{F}_{1}$ trees among four cross-types, based on the genotyping results.

\section{Autumn Freezing Test}

We conducted freezing tests on the $\mathrm{F}_{2}$ progeny three times during the autumn season using the method of Eiga and Sakai (1984). The potted seedlings were placed outdoors just before the test. Three freezing tests were conducted at approximately 2-week intervals: on 12 and 26 October, and 11 November (referred to as Tests 1, 2, and 3). Each freezing test was performed at the Institute of Low Temperature Science, Hokkaido University. The potted seedlings were placed in a dark chamber kept at $5^{\circ} \mathrm{C}$. After 
an overnight incubation, the temperature was lowered at a rate of $2^{\circ} \mathrm{C}$ per hour until the target temperature was reached. The target temperature was maintained for $4 \mathrm{~h}$, and then increased at a rate of $2^{\circ} \mathrm{C}$ per hour to $5^{\circ} \mathrm{C}$. For Test 1 , the target temperature was $-15^{\circ} \mathrm{C}$. For Tests 2 and 3 , the target temperatures were -15 and $-30^{\circ} \mathrm{C}$. The seedlings were kept in the growth chamber for 14 days with a 12 -h photoperiod (the photosynthetic photon flux density was $100 \mu \mathrm{mol} \mathrm{m} \mathrm{m}^{-2} \mathrm{~s}^{-1}$ during the day). We measured freezing damage using the visual scoring method of Lindgren and Hallgren (1993). Freezing damage was scored using six classes of needle discoloration (brown needles) as follows: 0 (no damage), 1 (1-20\% of needles were discolored), 2 (21-40\% discolored), 3 (41-60\% discolored), 4 (61-80\% discolored), and 5 (81-100\% discolored). For each temperature at each time point, we used $10 \mathrm{~F}_{2}$ seedlings from each $\mathrm{F}_{1}$ mother tree. For some maternal trees with fewer seedlings, we used seven seedlings. In total, 605 seedlings were used in the freezing test $(121$ seedlings $\times 5$ test conditions).

\section{Data Analysis}

Because no freezing damage was observed in the $-15^{\circ} \mathrm{C}$ treatment in Tests 2 and 3, we excluded these data from subsequent analysis. Therefore, three test conditions were defined: $\mathrm{T}_{1}$ involved freezing at $-15^{\circ} \mathrm{C}$ in Test $1, \mathrm{~T}_{2}$ involved freezing at $-30^{\circ} \mathrm{C}$ in Test 2 , and $\mathrm{T}_{3}$ involved freezing at $-30^{\circ} \mathrm{C}$ in Test 3. For each condition, we used a nested ANOVA to study the effect of maternal cross-type and the effect of mother trees on freezing damage in the $\mathrm{F}_{2}$ progeny, using the following model:

$$
Y_{i j k}=\mu+C_{i}+M_{j}\left(C_{i}\right)+E_{i j k},
$$

(Model 1)

where $Y_{i j k}$ is the freezing damage score of the $k$-th progeny $(k ; 1$ $10)$ of the $j$-th mother tree $(j ; 1-4)$ in the $i$-th cross-type $(i ; 1-4), \mu$ is the general mean, $C_{i}$ is the effect of the $i$-th cross-type, $M_{j}\left(C_{i}\right)$ is the effect of the $j$-th mother tree nested in the $i$-th cross-type, and $E_{i j k}$ is the residual error.

We also evaluated the effect of low-elevation and highelevation plant genomes on freezing damage using the following statistical model that includes all test conditions. We assumed that freezing damage in the $\mathrm{F}_{2}$ progeny is affected by the genetic inheritance, test conditions, and mother tree. Therefore, we constructed the full model with all assumed effects, as follows:

$$
\begin{gathered}
Y_{i j k l}=\mu+C_{i}+T_{l}+C_{i j} \times T_{l}+M_{j}\left(C_{i}\right)+ \\
M_{j}\left(C_{i}\right) \times T_{l}+E_{i j k l},
\end{gathered}
$$

(Models 2-5)

where $Y_{i j k l}$ is the freezing damage score of the $k$-th progeny of the $j$-th mother tree in the $i$-th cross-type under the $l$-th test condition $(l ; 1-3), \mu, C_{i}$ and $M_{j}\left(C_{i}\right)$ are the same as in Model 1 , and $T_{l}$ is the effect of the $l$-th test condition. In this full model, we regard the model element $C$ as representing the effect of the plant genome (genetic effect). Then, in the analysis, $C, T$, and their interaction $(C \times T)$ are treated as fixed effects, whereas $M(C)$ and its interaction with $T$ are treated as random effects. Because damage is an ordinal variable (Ishizuka et al., 2015), we used an ordered probit mixed model (Lee, 1992). Specifically, we used the cumulative link mixed model (CLMM) function in the "ordinal" package of R 3.1.2 (R Development Core Team, 2014). CLMM uses a maximum likelihood approach with the Laplace approximation and adaptive Gauss-Hermite quadrature (see Christensen, 2014).

We then assessed which types of variables were appropriate for the effect of the plant genome $(C)$ to describe the freezing damage score. Therefore, we used the following four types of the genetic effects as $C$ in Models 2-5:

Model 2: Linear effect $(0$ for $\mathrm{L} \times \mathrm{L} ; 0.25$ for $\mathrm{L} \times \mathrm{H}$ and $\mathrm{H} \times \mathrm{L}$; 0.5 for $\mathrm{H} \times \mathrm{H}$ )

Model 3: Categorical effect $(\mathrm{L} \times \mathrm{L} ; \mathrm{L} \times \mathrm{H} ; \mathrm{H} \times \mathrm{L} ; \mathrm{H} \times \mathrm{H})$

Model 4: Categorical interaction effect ("NoHyb" for $\mathrm{L} \times \mathrm{L}$ and $\mathrm{H} \times \mathrm{H}$; "Hyb $\mathrm{HH}_{\mathrm{LH}}$ " for $\mathrm{L} \times \mathrm{H}$; "Hyb $\mathrm{HL}_{\mathrm{HL}}$ " for $\mathrm{H} \times \mathrm{L}$ )

Model 5: Linear effect + interaction effect $(0$ for $\mathrm{L} \times \mathrm{L}$; $0.25+\alpha$ for $\mathrm{L} \times \mathrm{H} ; 0.25-\alpha$ for $\mathrm{H} \times \mathrm{L} ; 0.5$ for $\mathrm{H} \times \mathrm{H})$.

In Model 2, the proportion of high-elevation genome inherited from the maternal parent was used. Numeric values indicating the linear effect of the maternal genome origin were assigned to $C$. The highest value was assigned to the $\mathrm{H} \times \mathrm{H}$ cross-type, whereas the lowest value, 0 , was assigned to the $\mathrm{L} \times \mathrm{L}$ cross-type. Model 2 should show a good fit if freezing damage was closely related to the amount of high-elevation genome inherited from the maternal trees (i.e., quantitative trait). In Model 3, C was set to one of four categorical values indicating the crosstype of the maternal trees. Model 3 should fit well if the maternal origin is important, but the proportion of high-elevation genome is not. Model 4 included a genome interaction effect. As described above, $C$ was set to one of three categorical values: NoHyb, $\mathrm{Hyb}_{\mathrm{LH}}$, or $\mathrm{Hyb}_{\mathrm{HL}}$. In Model 5, we included both the cross-type linear effect and genome interaction effect. $C$ was partitioned into the combination of the variables used in Models 2 and 4.

We used a model selection procedure to exclude the variables that did not improve the model fit. The Akaike Information Criterion (AIC) was used to consider goodness-of-fit and number of parameters (Johnson and Omland, 2004). Within each model (Models 2-5), a backward stepwise procedure from the full model was performed to determine the most effective variable sets. Then, we compared the AIC values among all candidate models and selected the model with the lowest AIC value as the best model for explaining freezing damage in the $\mathrm{F}_{2}$ progeny. All statistical analyses in this study were conducted using $\mathrm{R}$ 3.1.2 (R Development Core Team, 2014).

\section{RESULTS}

\section{Paternity Analysis}

All seven SSR markers were polymorphic. For the nSSR markers, the average number of alleles per locus $(N)$ was 15.0, ranging from 7 for As08 to 21 for As16 and NFH15. For the cpSSR markers, the numbers of haplotypes of Pt30141, Pt30204, and Pt71936 were 15, 13, and 7, respectively. The genotypes of the $22 \mathrm{~F}_{1}$ candidate pollen parents differed from each other (see Supplemental Table). Genetic diversity statistics for the four nSSR markers are summarized for the $F_{1}$ and $F_{2}$ materials in Table 3. 
A $\quad 0 \quad 61218$ (No. of observations)

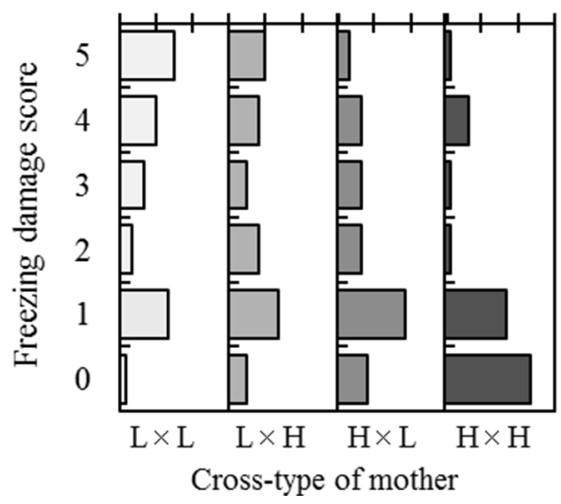

B 061218 (No. of observations)

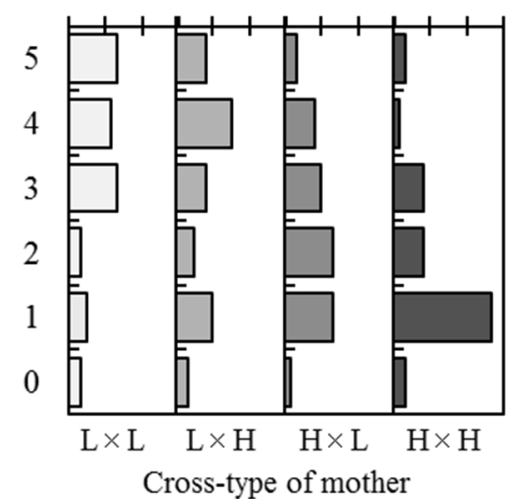

C 0102030 (No. of observations)

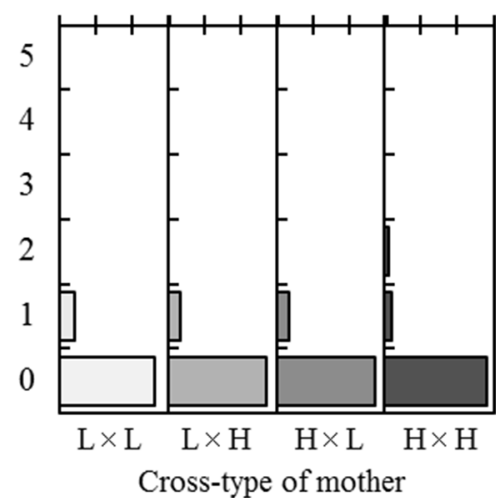

FIGURE 2 | Freezing damage of $\mathbf{F}_{2}$ progeny after a freezing test at $-15^{\circ} \mathbf{C}$ in Test $\mathbf{1}(\mathbf{A}),-30^{\circ} \mathbf{C}$ in Test $\mathbf{2}(\mathbf{B})$, or $-\mathbf{3 0} 0^{\circ} \mathbf{C}$ in Test $\mathbf{3}(\mathbf{C})$. Three freezing tests were conducted in autumn at a 2-week interval. The freezing damage scores range from 5 (complete needle discoloration) to 0 (no discoloration). Observed frequencies were shown by arraying the cross-type of each mother (on the lower $x$-axis). The maximum scale of the number of observations (on the top x-axis) was set to 18 for each of the four cross-types in Tests 1 and 2, and set to 30 for each of the four cross-types in Test 3.

The genetic characteristics of the $F_{2}$ progeny were consistent among their maternal groups. The average number of alleles in the $F_{2}$ progeny was smaller than that in the $F_{1}$ trees, which was caused by maternal sharing ( 13 out of $353 \mathrm{~F}_{1}$ trees; Table 1 ). In contrast, their observed heterozygosity $\left(\mathrm{H}_{\mathrm{O}}\right)$ was higher in the $\mathrm{F}_{2}$ progeny than in the $\mathrm{F}_{1}$ trees, resulting in a negative fixation index (FIS).

Paternity analysis using four nSSR markers showed that $12 \mathrm{~F}_{2}$ progeny had a father from the candidate $F_{1}$ pollen parent group. By adding the results of cpSSR analysis, seven $\mathrm{F}_{2}$ progeny out of 12 were not excluded. For these seven $\mathrm{F}_{2}$ progeny, the cross-type of all of the assigned $F_{1}$ fathers was $L \times L$. There were no progeny with genotypes composed solely of maternal alleles, excluding the possibility of selfing. Moreover, most of the $\mathrm{F}_{2}$ progeny had novel alleles in comparison with the candidate $\mathrm{F}_{1}$ pollen donors. Allowing for genotyping errors, the proportions of selfing, mating between $\mathrm{F}_{1}$ trees, and mating with outside trees were 0 , 8.7 (7 samples), and 91.3\% (73 samples), respectively.

\section{Autumn Freezing Test and Model Selection}

Freezing damage scores in the $\mathrm{F}_{2}$ progeny ranged from 0 to 5 for treatment $\mathrm{T}_{1}\left(-15^{\circ} \mathrm{C}\right.$ in Test 1$)$ and treatment $\mathrm{T}_{2}\left(-30^{\circ} \mathrm{C}\right.$ in Test 2; Figure 2). In $\mathrm{T}_{1}$, the most frequent damage scores for the progeny belonging to the $\mathrm{L} \times \mathrm{L}$ and $\mathrm{H} \times \mathrm{H}$ cross-types were $5(30.0 \%)$ and $0(45.2 \%)$, respectively. For the hybrid cross-types $(\mathrm{L} \times \mathrm{H}$ and $\mathrm{H} \times \mathrm{L})$, a score of 1 was most common $(26.7 \%$ for $\mathrm{L} \times \mathrm{H}$ and $36.7 \%$ for $\mathrm{H} \times \mathrm{L}$ ). In $\mathrm{T}_{2}$, the most frequent damage score for the $\mathrm{H} \times \mathrm{H}$ cross-type was 1 (51.6\%). In contrast, high damage scores ( 4 and 5 ) were often observed for the $\mathrm{L} \times \mathrm{L}, \mathrm{L} \times \mathrm{H}$, and $\mathrm{H} \times \mathrm{L}$ cross-types. In $\mathrm{T}_{3}\left(-30^{\circ} \mathrm{C}\right.$ in Test 3$)$, most progeny showed no damage, regardless of the cross-type (Figure 2C).

The ANOVA indicated a significant difference among mother trees within cross-types $[M(C)]$ for treatment $\mathrm{T}_{1}$ (Table 4). For treatment $\mathrm{T}_{2}$, a significant difference was detected among maternal cross-types $(C)$, but not among mother trees $[M(C)]$.
TABLE 4 | ANOVA of freezing damage in the $F_{2}$ progeny for each test condition, including degrees of freedom (DF), mean square (MS) and $F$-value $(F)$.

\begin{tabular}{|c|c|c|c|c|c|c|c|}
\hline \multirow[b]{2}{*}{ Source } & \multirow[b]{2}{*}{$D F$} & \multicolumn{2}{|c|}{$\mathbf{T}_{1}$} & \multicolumn{2}{|c|}{$\mathbf{T}_{2}$} & \multicolumn{2}{|c|}{$\mathbf{T}_{3}$} \\
\hline & & MS & $\boldsymbol{F}$ & MS & $F$ & MS & $F$ \\
\hline C & 3 & 21.47 & 3.30 & 13.46 & $4.54^{*}$ & 0 & - \\
\hline$M(C)$ & 9 & 6.50 & $2.78^{* *}$ & 2.97 & 1.48 & 0 & - \\
\hline Error & 108 & 2.34 & & 2.00 & & 0 & \\
\hline
\end{tabular}

C, cross-type; $M(C)$, mother tree nested in the cross-type; $T_{1},-15^{\circ} \mathrm{C}$ in Test 1 ; $T_{2},-30^{\circ} \mathrm{C}$ in Test 2; $T_{3},-30^{\circ} \mathrm{C}$ in Test 3. ${ }^{*} P<0.05,{ }^{*} P<0.01$.

For treatment $\mathrm{T}_{3}$, however, statistical analysis was not possible due to limited variation in freezing damage score, as shown in Figure 2.

Model selection for each of the four candidate models (Models 2-5) indicated that the interaction terms $C \times T$ and $M(C) \times T$ should be excluded from Models 2, 3, and 5 (Table 5). In Model 4 , the $C$ effect was also excluded. This indicates the effect of the mother trees assumed in Model 4 (i.e., non-hybrid vs. hybrid) was not useful for predicting freezing damage in the $\mathrm{F}_{2}$ progeny. A model comparison based on AIC values revealed that Model 2, which included the cross-type linear effect, was the best model (Table 5). The effects included in this model were $C, T$, and $M(C)$. The estimated coefficients of these variables are shown in Table 6. A significant negative effect was observed for $C$, indicating that the freezing damage tended to be lower in the progeny that inherited a higher proportion of the high-elevation genome.

\section{DISCUSSION}

Freezing damage differed among seedlings of A. sachalinensis early in the study period, but was barely observed in the final test conducted in November (Figure 2). This demonstrates 
TABLE 5 | Candidate model components and Akaike Information Criterion (AIC) values after model selection.

\begin{tabular}{|c|c|c|c|}
\hline \multirow[t]{2}{*}{ Candidate moc } & \multicolumn{3}{|r|}{ M } \\
\hline & \multicolumn{3}{|c|}{ C } \\
\hline Model 2 & \multicolumn{3}{|l|}{$+($ Linear $)$} \\
\hline Model 3 & \multicolumn{3}{|c|}{ + (Categorical) } \\
\hline Model 4 & & \multicolumn{2}{|c|}{ - (Categorical interaction) } \\
\hline Model 5 & \multicolumn{3}{|c|}{ + (Linear with categorical interaction) } \\
\hline \multicolumn{4}{|c|}{$\begin{array}{l}\text { For each model, variables were retained (represented by }+ \text { ) or excluded }(-) \text { by a s } \\
\text { Models } 2-5 \text {, different types of effects were used for model component } C \text {. } \\
C, T, C \times T \text { : fixed effect of plant genome, the test condition, and their interaction, } \\
M(C), M(C) \times T \text { : random effect of the mother tree nested in the cross-type and it }\end{array}$} \\
\hline \multicolumn{4}{|c|}{$\begin{array}{l}\text { TABLE } 6 \text { | Estimated parameters for Model } 2 \text {, the best model among all } \\
\text { candidate models (Models } 2-5 \text { ) for predicting freezing damage in the } F_{2} \\
\text { progeny (standard errors are in parentheses). }\end{array}$} \\
\hline \multicolumn{2}{|l|}{ Model 2} & Coefficient & $p$-value \\
\hline \multirow[t]{4}{*}{ Fixed effect } & $C$ (Linear) & $-2.440(0.580)$ & $<0.001$ \\
\hline & $T(T 1)$ & 0 & - \\
\hline & $\left(\mathrm{T}_{2}\right)$ & $0.336(0.136)$ & 0.014 \\
\hline & $\left(T_{3}\right)$ & $-8.277(101.7)$ & 0.935 \\
\hline Random effect & M (C) (13 categories) & $\approx 0(0.206)$ & \\
\hline
\end{tabular}

The negative effect of plant genome (C) indicates that the progeny with a higher proportion of the high-elevation genome tend to show less freezing damage.

the development of freezing tolerance over time. In addition, freezing damage differed among maternal cross-types of the $\mathrm{F}_{2}$ progeny, even though the mother trees were grown in the same environment (Figure 2). Genetic variation in autumn phenology was relatively clear. Seedlings that inherited a greater proportion of the high-elevation genome displayed earlier cold acclimation. We used visual scoring, but alternative quantitative evaluations (e.g., by chlorophyll fluorescence or electrolytic leakage) are also used as indicators of cold hardiness (Lindgren and Hallgren, 1993; Ehlert and Hincha, 2008). Although quantitative evaluation is a powerful tool, the accuracy and efficiency of these alternative measures may be compromised if the plants have small leaves. In the present study, most seedlings developed thin needles, making a quantitative measurement difficult. In contrast, discoloration occurred evenly, making differences in freezing damage clear and comparable among seedlings. In addition, there is a strong correlation $(r=0.762)$ between our scoring method and chlorophyll fluorescence (evaluated by the $F_{\mathrm{v}} / F_{\mathrm{m}}$ value) in A. sachalinensis (Ishizuka et al., 2015). Thus, our evaluation method is sufficient for detecting phenotypic variation associated with cold acclimation in this species.

In studies of other boreal conifers, genetic variation in autumn phenology and associations with the climate of origin indicated adaptation to the local climate (Rehfeldt, 1989; Skrøppa and Magnussen, 1993; Oleksyn et al., 1998; Savolainen et al., 2004; Notivol et al., 2007; Mimura and Aitken, 2010). In our previous study using reciprocally transplanted materials of A. sachalinensis, we found clinal variation in the timing of autumn cold acclimation along an elevational gradient (Ishizuka et al., 2015). Here, we further evaluated the effects of genetic background of the trees using molecular markers and statistical models to improve our understanding of the local adaptation and the evolution of autumn cold acclimation.

\section{Paternity Analysis}

The combined use of nSSR and cpSSR markers made it possible to assign pollen parents to $A$. sachalinensis seedlings. We assigned 22 candidate $F_{1}$ pollen parents to the $F_{2}$ progeny with consideration for genotyping error and assignment confidence (Slavov et al., 2005). We assumed that cryptic gene flow had little effect because the genetic origin of the $F_{1}$ trees was different from that of the artificial forests surrounding the $F_{1}$ planting site. Therefore, when the paternity analysis found no possible fathers among the candidates, we assumed that the pollen parent was outside of the $\mathrm{F}_{1}$ planting site, and presumably derived from the surrounding mature plantations.

The small paternal contribution from the $F_{1}$ trees $(8.7 \%)$ indicated a high level of pollen flow from outside pollen sources (91.3\%). High levels of pollen contamination have been reported to be a severe problem in seed orchard management (Wheeler and Jech, 1992). When a seed orchard is young, the proportion of outside pollen flow tends to be extremely high. For example, Ozawa et al. (2009) performed paternity analysis of collected seeds in a young Pinus densiflora seed orchard, and detected $82 \%$ outside pollen flow. The results of that study suggested that the amount of pollen brought to the female strobili from the male strobili within the seed orchard was markedly lower than that of immigrant pollen brought from surrounding mature forests. In the present study, only $6.2 \%$ of the $\mathrm{F}_{1}$ parents were flowering due to their young age (29 years old) and small size (Table 1). As suggested by Ozawa et al. (2009), the amount of pollen from the $\mathrm{F}_{1}$ planting site must be lower than that from the surrounding mature plantations. Therefore, the results obtained by paternity analysis are reasonable.

If the timing of pollen shed from surrounding plantations and the receptivity of female strobili of the $F_{1}$ trees are mismatched, outside pollination will occur rarely. Indeed, Sasaki (1983) reported that the flowering phenology of $A$. sachalinensis at the plantation forest at $1100 \mathrm{~m}$ was delayed by approximately 2 weeks compared with that at $530 \mathrm{~m}$. If the difference in flowering phenology is genetically controlled, the timing of female flowering of $F_{1}$ trees derived from a crossing among highelevation parents may differ from that of male flowering of local (low-elevation) trees. However, the flowering phenology of the $\mathrm{F}_{1}$ 
trees which were planted at the same environment overlapped, as described by Goto et al. (2011). These results suggest that environmental factors, rather than ontogenetic control, strongly affected the flowering phenology of A. sachalinensis (Sasaki, 1983; Goto et al., 2011). Therefore, it is not surprising that outside pollen flow was predominant at our $\mathrm{F}_{1}$ planting site.

Evidence of frequent outcrossing was also seen in the genetic parameters obtained using nSSRs. Observed heterozygosity $\left(H_{\mathrm{O}}\right)$ increases and the fixation index ( $\left.F_{\text {IS }}\right)$ decreases when mating occurs between local and non-local populations (Hamrick and Godt, 1996). In our study, $H_{\mathrm{O}}$ of the $\mathrm{F}_{2}$ was higher than that of natural stands (Lian et al., 2008; Table 2). A large decrease in $F_{\text {IS }}$ was also detected between the $F_{1}$ and $F_{2}$ generations, although there were only small differences within the $F_{2}$ (Table 2). The negative $F_{\text {IS }}$ in $F_{2}$ indicated that the chances of mating between an $F_{1}$ mother and its relatives were low. These results support our conclusions concerning pollen flow from outside the $F_{1}$ planting site.

We concluded that only a few $F_{1}$ fathers contributed to the $\mathrm{F}_{2}$ progeny because of the high levels of pollen flow from the surrounding mature plantations. Moreover, the $F_{1}$ trees that were assigned as fathers (seven progeny) were all derived from the $\mathrm{L} \times \mathrm{L}$ cross-type. This indicates that the high-elevation plant genome from the $F_{1}$ population was not inherited by the $F_{2}$ population to any great degree.

\section{Autumn Freezing Test and Model Selection}

Our modeling analysis revealed that the regulation of autumn cold acclimation could be well explained by the linear effect of the genome origin. The model using the expected proportion of high-elevation genome as a fixed effect was selected as the best model (Table 5). In this model, variation in autumn cold acclimation was explained by variation in the maternal genome composition. The $\mathrm{F}_{2}$ progeny that inherited a greater proportion of the high-elevation genome showed earlier cold acclimation.

Because of epigenetic phenomena, such as maternal effects and 'after' effects, the prediction of phenotypic values for quantitative traits can be a complex process (Howe et al., 2003; Johnsen et al., 2005; Kvaalen and Johnsen, 2008; Cané-Retamales et al., 2011). In some cases, the performance of the progeny is subjected to a significant epigenetic effect (Johnsen et al., 2005; Kvaalen and Johnsen, 2008). An experiment with Picea abies revealed that autumn phenological traits (date of bud set) was related to the daylength and/or thermal conditions during fertilization and seed maturation (Johnsen et al., 2005). Moreover, the performance of the progeny may be influenced by phenomena related to epistasis (Sykes et al., 2006). Sykes et al. (2006) used the crossbred progeny derived from a specific combination of crosses in P. taeda, and successfully measured the effects of genomic interactions in the

\section{REFERENCES}

Aitken, S. N., and Hannerz, M. (2001). "Genecology and gene resource management strategies for conifer cold hardiness," in Conifer Cold Hardiness, chemical contents of woody materials. In the present study, however, the model analysis indicated that epigenetic phenomena and the cross-type-dependent maternal effect were not likely to have played a major role (Table 5). In comparison with models considering such effects, the model including only the effect of genome origin showed the best fit. This result could be partly explained by the fact that all maternal trees were exposed to the same environmental conditions. Moreover, in the absence of a specific cross-type effect, it would be reasonable to expect that the autumn cold acclimation of $A$. sachalinensis would show a linear pattern based on the proportion of low-elevation and high-elevation plant genomes.

This interpopulational regulation of autumn phenology may be one of the factors driving the local adaptation of conifers (Aitken and Hannerz, 2001; Howe et al., 2003). For A. sachalinensis, clinal variation in the timing of autumn cold acclimation along an elevational gradient is one of the elevationdependent adaptive traits. Each population adapts to the local climate, with a trade-off between the avoidance of freezing damage and extension of the growth period (Ishizuka et al., 2015). The genome-based control of phenological traits may be the mechanism responsible for the elevation-dependent adaptation of this species.

The genetic control of ecologically relevant traits is important in forest management. Potential genetic changes in future generations must be taken into consideration, particularly considering projections of rapid global warming (Jump and Penuelas, 2005; Aitken et al., 2008; Ishizuka and Goto, 2012). If a target species shows strong genetic variation that is larger than the phenotypic plasticity, it may be important to redistribute the genes that confer optimal performance in the changing climate (Aitken et al., 2008). For A. sachalinensis, it may be difficult to track rapid climate change because of the mismatch of locally adapted autumn phenology. However, the presence of adaptive genes and their potential for climatic adaptation have not been sufficiently examined. Future studies may be needed to evaluate this subject in detail by applying powerful molecular techniques, such as the analysis of quantitative trait loci and/or genome scanning.

\section{ACKNOWLEDGMENT}

The authors are deeply grateful to Glenn Howe for critical comments on the manuscript.

\section{SUPPLEMENTARY MATERIAL}

The Supplementary Material for this article can be found online at: http://journal.frontiersin.org/article/10.3389/fpls.2015.00890

eds F. J. Bigras and S. J. Columbo (Dordrecht: Kluwer Academic Publishers), 23-53.

Aitken, S. N., Yeaman, S., Holliday, J. A., Wang, T. L., and Curtis-McLane, S. (2008). Adaptation, migration or extirpation: climate change outcomes for 
tree populations. Evol. Appl. 1, 95-111. doi: 10.1111/j.1752-4571.2007.00 013.x

Cané-Retamales, C., Mora, F., Vargas-Reeve, F., Perret, S., and Contreras-Soto, R. (2011). Bayesian threshold analysis of breeding values, genetic correlation and heritability of flowering intensity in Eucalyptus cladocalyx under arid conditions. Euphytica 178, 177-183. doi: 10.1007/s10681-010-0292-y

Christensen, R. H. B. (2014). Ordinal - Regression Models for Ordinal Data. $R$ Package Version 2015.1-21. Available at: https://www.cran.r-project.org/ package=ordinal/ [Accessed February 15, 2015].

Chuine, I. (2010). Why does phenology drive species distribution? Philos. Trans. $R$. Soc. B Biol. Sci. 365, 3149-3160. doi: 10.1098/rstb.2010.0142

Ehlert, B., and Hincha, K. D. (2008). Chlorophyll fluorescence imaging accurately quantifies freezing damage and cold acclimation responses in Arabidopsis leaves. Plant Methods 4, 12. doi: 10.1186/1746-4811-4-12

Eiga, S., and Sakai, A. (1984). Altitudinal variation in freezing resistance of Saghalien fir (Abies sachalinensis). Can. J. Bot. 62, 156-160. doi: 10.1139/b84025

Fujikawa, S., Ukaji, N., Nagao, M., Yamane, K., Takezawa, D., and Arakawa, K. (2006) "Functional role of winter-accumulating proteins from mulberry tree in adaptation to winter-induced stresses," in Cold Hardiness in Plants: Molecular Genetics, Cell Biology and Physiology, eds T. H. H. Chen, M. Uemura, and S. Fujikawa (Oxfordshire: CABI Publishers), 181-202.

Goto, S., Iijima, H., Ogawa, H., and Ohya, K. (2011). Outbreeding depression caused by intraspecific hybridization between local and nonlocal genotypes in Abies sachalinensis. Restor. Ecol. 19, 243-250. doi: 10.1111/j.1526100X.2009.00568.x

Hamrick, J. L., and Godt, M. J. W. (1996). Effects of life history traits on genetic diversity in plant species. Philos. Trans. R. Soc. Lon. B Biol. Sci. 351, 1291-1298. doi: $10.1098 /$ rstb.1996.0112

Hansen, O. K., Vendramin, G. G., Sebastiani, F., and Edwards, K. J. (2005). Development of microsatellite markers in Abies nordmanniana (Stev.) Spach and cross-species amplification in the Abies genus. Ecol. Notes 5, 784-787. doi: 10.1111/j.1471-8286.2005.01062.x

Howe, G. T., Aitken, S. N., Neale, D. B., Jermstad, K. D., Wheeler, N. C., and Chen, T. H. H. (2003). From genotype to phenotype: unraveling the complexities of cold adaptation in forest trees. Can. J. Bot. 81, 1247-1266. doi: 10.1139/ b03-141

Igarashi, Y. (1996). A late glacial climatic reversion in Hokkaido, northeast Asia, inferred from the Larix pollen record. Quat. Sci. Rev. 15, 989-995. doi: 10.1016/S0277-3791(96)00005-4

Ishizuka, W., and Goto, S. (2012). Modeling intraspecific adaptation of Abies sachalinensis to local altitude and responses to global warming, based on a 36-year reciprocal transplant experiment. Evol. Appl. 5, 229-244. doi: 10.1111/j.1752-4571.2011.00216.x

Ishizuka, W., Ono, K., Hara, T., and Goto, S. (2015). Use of intraspecific variation in thermal responses for estimating an elevational cline in the timing of cold hardening in a sub-boreal conifer. Plant Biol. 17, 177-185. doi: $10.1111 /$ plb.12214

Johnsen, Ø, Dæhlen, O. G., Østreng, G., and Skrøppa, T. (2005). Daylength and temperature during seed production interactively affect adaptive performance of Picea abies progeny. New Phytol. 168, 589-596. doi: 10.1111/j.14698137.2005.01538.x

Johnson, J. B., and Omland, K. S. (2004). Model selection in ecology and evolution. Trends Ecol. Evol. 19, 101-108. doi: 10.1016/j.tree.2003.10.013

Jump, A. S., and Penuelas, J. (2005). Running to stand still: adaptation and the response of plants to rapid climate change. Ecol. Lett. 8, 1010-1020. doi: 10.1111/j.1461-0248.2005.00796.x

Kalinowski, S. T., Taper, M. L., and Marshall, T. C. (2007). Revising how the computer program CERVUS accommodates genotyping error increases success in paternity assignment. Mol. Ecol. 16, 1099-1106. doi: 10.1111/j.1365294X.2007.03089.x

Kato, R. (1952). The vegetation of the Tokyo University Forest in Hokkaido (in Japanese with English summary). Bull. Tokyo Univ. For. 43, $1-18$.

Kozlowski, T. T., and Pallardy, S. G. (2002). Acclimation and adaptive responses of woody plants to environmental stresses. Bot. Rev. 68, 270-334. doi: 10.1663/0006-8101(2002)068[0270:AAAROW]2.0.CO;2
Kurahashi, T. (1995). Growth pattern of the F1 trees derived from reciprocal crosses between low and high elevation populations in Abies sachalinensis. Rep. JSPS KAKENHI 04806020, 44-49.

Kurahashi, A., and Hamaya, T. (1981). Variation of morphological characters and growth response of Sakhalin fir (Abies sachalinensis) in different altitude (in Japanese with English summary). Bull. Tokyo Univ. For. 71, 101-151.

Kvaalen, H., and Johnsen, $\varnothing$ (2008). Timing of bud set in Picea abies is regulated by a memory of temperature during zygotic and somatic embryogenesis. New Phytol. 177, 49-59.

Lee, J. (1992). Cumulative logit modelling for ordinal response variables: applications to biomedical research. Bioinformatics 8, 555-562. doi: 10.1093/bioinformatics/8.6.555

Lian, C. L., Goto, S., and Hogetsu, T. (2007). Microsatellite markers for Sachalin fir (Abies sachalinensis Masters). Mol. Ecol. Notes 7, 896-898. doi: 10.1111/j.14718286.2007.01741.x

Lian, C. L., Goto, S., Kubo, T., Takahashi, Y., Nakagawa, M., and Hogetsu, T. (2008). Nuclear and chloroplast microsatellite analysis of Abies sachalinensis regeneration on fallen logs in a subboreal forest in Hokkaido. Jpn. Mol. Ecol. 17, 2948-2962. doi: 10.1111/j.1365-294X.2008.03 802.x

Liepelt, S., Kuhlenkamp, V., Anzidei, M., Vendramin, G. G., and Ziegenhagen, B. (2001). Pitfalls in determining size homoplasy of microsatellite loci. Mol. Ecol. Notes 1, 332-335. doi: 10.1046/j.1471-8278.2001.00085.x

Lindgren, K., and Hallgren, J. E. (1993). Cold acclimation of Pinus contorta and Pinus sylvestris assessed by chlorophyll fluorescence. Tree Physiol. 13, 97-106. doi: 10.1093/treephys/13.1.97

Mimura, M., and Aitken, S. N. (2010). Local adaptation at the range peripheries of Sitka spruce. J. Evol. Biol. 23, 249-258. doi: 10.1111/j.1420-9101.2009.01 910.x

Nakata, M., Tanaka, H., and Yagi, H. (1994). Altitudinal changes in vegetation and soils on Mt. Dairoku, central Hokkaido, Japan (in Japanese with English summary). Jpn. J. Ecol. 44, 33-47.

Notivol, E., Garcia-Gil, M. R., Alia, R., and Savolainen, O. (2007). Genetic variation of growth rhythm traits in the limits of a latitudinal cline in Scots pine. Can. J. Forest Res. 37, 540-551. doi: 10.1139/X06-243

Oleksyn, J., Modrzynski, J., Tjoelker, M. G., Zytkowiak, R., Reich, P. B., and Karolewski, P. (1998). Growth and physiology of Picea abies populations from elevational transects: common garden evidence for altitudinal ecotypes and cold adaptation. Funct. Ecol. 12, 573-590. doi: 10.1046/j.1365-2435.1998.00 236.x

Ozawa, H., Watanabe, J., Chen, H., Isoda, K., and Watanabe, A. (2009). The impact of phonological and artificial factors on seed quality in a nematode-resistant Pinus densiflora seed orchard. Silvae Genetica 58, 145-152.

Peakall, R., and Smouse, P. E. (2012). GenAlEx 6.5: genetic analysis in Excel. Population genetic software for teaching and research. Bioinformatics 28, 2537-2539.

R Development Core Team (2014). R: A Language and Environment for Statistical Computing. Vienna: R Foundation for Statistical Computing.

Rehfeldt, G. E. (1989). Ecological adaptations in Douglas-fir (Pseudotsuga menziesii var. glauca) - a synthesis. Forest Ecol. Manage. 28, 203-215. doi: 10.1016/03781127(89)90004-2

Saho, H., Takahashi, I., and Kurahashi, A. (1994). "Relationship between the elevation of seed collecting sites and the susceptibility of Abies sachalinensis to Scleroderris lagerbergii in Hokkaido, Japan," in Proceedings of a Joint Meeting of the IUFRO Working Party, Canker and Shoot Blight of Conifers, Vallombrosa, 224-247.

Sasaki, T. (1983). Phenology of forest trees and temperature in central Hokkaido, Japan (Japanese title is translated in English by authors). Shinrin Bunka Kenkyu $4,77-86$.

Savolainen, O., Bokma, F., Garcia-Gil, R., Komulainen, P., and Repo, T. (2004). Genetic variation in cessation of growth and frost hardiness and consequences for adaptation of Pinus sylvestris to climatic changes. Forest Ecol. Manage. 197, 79-89. doi: 10.1016/j.foreco.2004.05.006

Skrøppa, T., and Magnussen, S. (1993). Provenance variation in shoot growth components of Norway spruce. Silvae Genet. 42, $111-120$. 
Slavov, G. T., Howe, G. T., and Adams, T. (2005). Pollen contamination and mating patterns in a Douglas-fir seed orchard as measured by simple sequence repeat markers. Can. J. Forest Res. 35, 1592-1603. doi: 10.1139/x05-082

Sykes, R., Li, B., Isik, F., Kadla, J., and Chang, H. M. (2006). Genetic variation and genotype by environment interactions of juvenile wood chemical properties in Pinus taeda L. Ann. For. Sci. 63, 897-904. doi: 10.1051/forest:2006073

Toyooka, H., Sato, M., and Ishizuka, S. (1983). Distribution Map of the Sasa Group in Hokkaido, Explanatory Note (in Japanese). Sapporo: Forestry and Forest Products Research Institute, Hokkaido Branch, 36.

Tsumura, Y., and Suyama, Y. (1998). Differentiation of mitochondrial DNA polymorphisms in populations of five Japanese Abies species. Evolution 52, 1031-1042. doi: 10.2307/2411234

Vendramin, G. G., Lelli, L., Rossi, P., and Morgante, M. (1996). A set of primers for the amplification of 20 chloroplast microsatellites in Pinaceae. Mol. Ecol. 5, 595-598. doi: 10.1046/j.1365-294X.1996.00111.x
Vendramin, G. G., and Ziegenhagen, B. (1997). Characterization and inheritance of polymorphic plastid microsatellites in Abies. Genome 40, 857-864. doi: $10.1139 / \mathrm{g} 97-811$

Wheeler, N. C., and Jech, J. H. (1992). The use of electrophoretic markers in seed orchard research. New Forest. 6, 311-328. doi: 10.1007/BF00120650

Conflict of Interest Statement: The authors declare that the research was conducted in the absence of any commercial or financial relationships that could be construed as a potential conflict of interest.

Copyright (c) 2015 Ishizuka, Ono, Hara and Goto. This is an open-access article distributed under the terms of the Creative Commons Attribution License (CC BY). The use, distribution or reproduction in other forums is permitted, provided the original author(s) or licensor are credited and that the original publication in this journal is cited, in accordance with accepted academic practice. No use, distribution or reproduction is permitted which does not comply with these terms. 